\title{
Needs Analyses with LEGO® SERIOUS PLAY®
}

\author{
Tanja Kranawetleitner ${ }^{1}$, Heike Krebs ${ }^{2}$, Nina Kuhn ${ }^{3}$, Marietta Menner ${ }^{4}$ \\ 1,2, 3,4 University of Augsburg, Universitaetsstrasse 1a, 86159 Augsburg \\ tanja.kranawetleitnereamu.uni-augsburg.de
}

\begin{abstract}
In the development of companies, innovative methods, including game-based approaches, can support change management. Within the project "Education 4.0 for SMEs", LEGO® SERIOUS PLAY® (LSP) is used in small and medium-sized enterprises as a needs analysis based on the gamification approach. LSP is a methodology that stimulates free communication. It opens access to those types of knowledge that are otherwise difficult to reach or to express, like personal attitudes or values. Constructions using LEGO® bricks help to visualise this knowledge and to make abstract ideas tangible. Hence, it is a particularly suitable method for needs analysis in times of digitalisation. The paper presents first data collected using LSP in the business context, providing a first impression of the possibilities, limitations, and applications of this method.
\end{abstract}

Keywords: LEGO® SERIOUS PLAY®, Needs Analysis, Digitalisation, SMEs.

\section{Introduction}

In the past decades, large companies have increasingly used game-based methods for their strategic development. Gradually, however, small and medium-sized enterprises (SMEs) are also dealing with gamification approaches as an innovative tool for designing change processes, personnel development or product training [1]. Gamification elements can be applied to increase the motivation to deal with tasks that are unrelated to the game [2]. Using these elements, Game-Based-Learning can occur because "learning - or a flow of information - takes place [...] through gaming overall" [3].

The LEGO® SERIOUS PLAY® (LSP) gamification approach described below is a possibility of motivating employees to engage intensively with the development of the company. It can especially be used to identify possible fears and inhibitions about change and visualise these with the help of LEGO® bricks.

\section{LEGO® SERIOUS PLAY® - in Theory}

LSP, developed in 1996 by Johan Roos and Bart Victor within the LEGO® Company and released for public use in 2010, is a method for solving problems and developing ideas [4]. The initial thought was to support managers to more easily scrutinise their own view of the company and thus to optimise their performance [4]. Ideas and opinions are exchanged more easily using LSP - whether in groups or individual coaching 
sessions. Discussion and finding a solution are also encouraged [5]. In LSP, participants work manually with the bricks and describe as well as reflect their constructions afterwards. This enables a special form of creativity that leads to completely different perspectives. Besides, the representation of one's ideas by a self-created object simplifies and improves mutual understanding [4].

LSP relies on a theoretical framework described by four elements: Papert's theory of constructionism is based on Piaget's constructivism, but goes beyond it: "Constructionism is a way of making formal, abstract ideas and relationships more concrete, visible, tangible, manipulative and therefore easier to understand" [6]. Secondly, play always serves a certain purpose, is voluntary, structured and limited [6]. In play and thus in LSP, metaphors and storytelling are important aspects. The telling of stories does not only illustrate hopes and fears more clearly, but in an organizational context, it also serves a better resolution of conflicts, the socialization of new members and identification with the company. Metaphors are essential for understanding the opposite party better [6]. In addition, playing can cause a flow effect. This describes the immersion in a task, which is combined with enjoyment and forgetting oneself and the outside world [7]. Imagination is an interplay of describing, creating and questioning something. Different forms of imagination enable not only to represent and relate what is visible, including discovering new facets of known aspects, but also to develop something fundamentally new [6]. Finally, identity means self-image and self-understanding and points to the individual note of LSP [8].

\section{$3 \quad$ LEGO® SERIOUS PLAY® - in Practice}

LSP can be used in various areas, for example, in coaching, idea development, team building or product innovation. The construction work is carried out in different stages. It ranges from individual to shared, and system models [4]. Ordinarily, a workshop takes between three hours and one day [5]. The process includes not only the cycles of building, but also the subsequent phases of reflection and thus collaborative learning. Therefore, it should not only be applied as an icebreaker at the beginning or for convincing others of a certain opinion. Instead, one's own thoughts, ideas and attitudes should be presented, which are given a frame by the LEGO ${ }^{\circledR}$ bricks [5]. Moreover, LSP helps the participants immerse themselves in a topic, whether in personal or team development tasks or complex challenges in business contexts [9]. Nevertheless, according to The LEGO® Group itself, facilitators should check if the method is appropriate for the occasion before using it, as it might not be useful in all cases [5].

\section{$4 \quad$ LEGO® SERIOUS PLAY® - an exploratory study}

Talking about the future of work often includes considering new, possibly virtual or virtually augmented, spaces and the increasing use of digital tools. However, current studies show that the situation of companies concerning digitalisation is largely dependent on their size and branch [10]. Especially small and medium sized enterprises 
are lacking physical and personal resources for this digital transformation, although in principle, employees are interested in developing their knowledge [11].

This situation is the starting point of the project "Education 4.0 for SMEs". It aims at finding out more about possible support for SMEs in Germany in their digitalisation challenges, especially in terms of knowledge transfer. In order to increase the digital competences of staff and equip SMEs with suitable tools, a first step consists of a detailed assessment of the companies' requirements and the staff's need of support.

\subsection{Needs analysis in the project "Education 4.0 for SMEs"}

For this purpose, the project carries out a needs analysis after a preliminary discussion with the management, in which initial starting points have already been identified. The needs analysis intends to reify the discrepancy between the desired and the actual situation and thus has the aim of "analysing deficits in education, promotion and organisational development at the strategic, operational and individual level" [12].

The needs analysis focuses on the knowledge and attitudes of the employees concerning digitalisation. In addition to factual knowledge, especially experiential and implicit knowledge take centre stage. "These types of knowledge denote the hidden knowledge content, which knowledge carriers are largely unconscious of" [13], and which is difficult to express [14].

Apart from the collection of this evasive knowledge, it is important to find out about unspoken and critical issues, like reservations, difficulties, and obstacles at the personal and structural basis. From individual to organizational levels, the needs analysis should also uncover shortcomings of intentions (motivation), lack of abilities or competences (qualifications), and obstacles concerning access or permission (organizational development) [12]. All of those three, motivation, qualification and organizational development are part of the project "Education 4.0 for SMEs".

\subsection{LSP methodology in the project "Education 4.0 for SMEs"}

In the LSP workshop, the employees start with a warm-up exercise, building a simple model like a walrus according to original LEGO ${ }^{\circledR}$ instructions. Then they transform this model to include features associated with a digitalised company. After the individual presentations, which should not be interrupted for the benefit of an open atmosphere, further models show the staff's ideas of their departments after a successful process of digitalisation. These constructions are classified as "individual models" [4]. Only in the last step, the departments literally grow together and by discussing the individual parts and priorities, the participants jointly construct their ideal digital company ("shared and system model" [4]). During the whole workshop, each participant uses the same number and type of bricks (LSP Starter Kit).

Considering that using LSP as a method of inquiry is unprecedented in the area described, one main aspect is to find out more about the suitability of the method itself. Regarding the topic of digitalisation, three aims can be pursued, whereas this paper focuses on (2) and (3) in order to show the potential of LSP as a game-based approach: (1) Collect factual knowledge about participants; (2) Provoke individual expressions of attitudes and emotions; (3) Engender individual reflections of one's needs. 
In addition to the data collection by means of LSP in the field of digitalisation, at the end the participants fill in a questionnaire in which they evaluate the experienced LSP workshop (9 items with 5-point Likert scale ranging from "totally agree" to "totally disagree"). In order to gain as broad an insight as possible, the participants $(n=21)$ consist of heterogeneous representatives of the workforce of each participating SME (age, gender, education, part-time or full-time, department and company hierarchy).

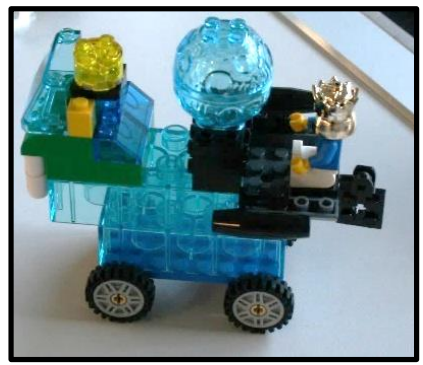

Fig. 1. Example of a modified walrus

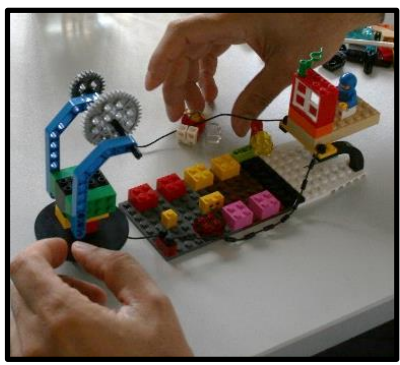

Fig. 2. Building a digitalised department

\subsection{Preliminary results}

First and foremost, LSP serves to elicit attitudes and emotions with the aim of finding out more about personal needs. This information is obtained by participants' explicit descriptions as well as their reflection and interpretation of their models, which are quoted in the following. For instance, a digitalised walrus might include wheels, a transparent "shield" in front of its eyes and might be built with or without a "driver" (quotations refer to the participants' presentations). Usually, the description goes along with the builder's own interpretation. Diversity appears not only due to varying types of construction (e.g. a "pillar" for "stability" instead of wheels for "speed, agility, flexibility"), but also by individual readings of the same materials: The mentioned "shield", for instance, was understood as a way of "protection" against the dangers of digitalisation or as a type of "glasses" to "see through". Whereas the former idea can indicate a possible reservation towards the challenges of digitalisation, the latter might suggest a less critical stance. Based on identical sets of bricks, the participants also build different constructions whose interpretation is similar. For example, the association of "speed" was embodied not only by wheels but also by a helicopter or plane. Individual interpretations (e.g. the figure of a driver who "steers" the digitalised company, or the co-presence of other figures showing that it is important for managers "to take their staff along") lead to the overt discussion of the employees' needs, values and attitudes personal statements, not usually mentioned thoughtlessly in an ordinary meeting.

\subsection{Evaluation of the method in the project "Education 4.0 for SMEs"}

The evaluation of using LSP in a business context for an assessment of the staff's attitudes and requirements concerning digitalisation in their company shows first implications for the further development of the method. The majority of those questioned $(n=$ 21) did not know and had not used the method before. Therefore, possible reservations 
against using LEGO $®$ were ruled out from the beginning. One of the main tenets of the method, namely its playfulness and enjoyable nature, were confirmed by a clear majority $(90 \%)$. Even more importantly, the method helped the employees to become aware of practical implications of digitalisation $(86 \%)$, and some even learned something new by participating $(76 \%)$. Only some employees found the method helpful to understand digitalisation in a company in general (38\%). The items about the communication of knowledge by the method point to the suggested low relevance of collecting factual knowledge (aim 1, see section 4.2).

\subsection{Discussion}

From a purely quantitative perspective, the small number of participants is problematic. However, although findings from the collected data can only count as indications rather than robust results, they clearly show the potential of LSP. For a comprehensive outcome, it should also be considered that most participants verbalise their thoughts and feelings already during the process of building. Therefore, the documentation or recording (obeying the rules of privacy protection) should span the whole workshop.

In addition, it is essential to discuss problems of accessibility. The participants may feel uncomfortable if they have little or no experience in playing with LEGO®. Moreover, LSP uses "new" types of bricks. This could lead to confusion and the necessity of more time to get to know the unknown bricks and thus to build with them.

Another aspect to mention is the diversity of the participants, starting with the risk that it may be difficult for people to structure their thoughts manually and to articulate their ideas metaphorically in retrospect. Besides, building with small LEGO ${ }^{\circledR}$ bricks might prove an obstacle for people with certain impairments, which could lead to their exclusion. Finally, especially in the corporate context some could also consider the method too "playlike", and for this reason do not take it seriously.

\section{$5 \quad$ Conclusion and perspectives}

Concluding, LSP has yielded promising results for the collection of individual assessments of possibly controversial topics. Additionally to the business context, the LSP approach has already been tested with students aged 13 and above. Apart from building the digitalised school of the future, their workshop tackled topics of Industry 4.0, such as the loss of jobs due to the use of robots, artificial intelligence, and others.

For the future, the project "Education 4.0 for SMEs" is planning to include further target groups. This will provide the opportunity to analyse the method itself in greater depth. Moreover, a transfer of LSP into the digital space is intended, raising the question how the lack of haptics of virtual LEGO ${ }^{\circledR}$ bricks influences the results. Finally, the use of LSP for learning will be tested. As the game-based learning approach can not only be applied to the "flow of information" [3] as in the present case, but also offers the possibility to generate learning itself, this might be a promising undertaking. In this vein, LSP can also be used for further qualification or other areas of application. 


\section{Acknowledgements}

The Project "Bildung 4.0 für KMU" ("Education 4.0 for SMEs", Grant number 01PA17014) is funded by the German Federal Ministry of Education and Research and the European Social Fund for Germany.

\section{References}

1. Niedermeier, S., Müller, C.: Game-Based-Learning in Aus- und Weiterbildung - von der Idee zur Umsetzung. In: Wachtler, J., Ebner, M., Gröblinger, O., Kopp, M., Bratengeyer, E., Steinbacher, H.-P., Freisleben-Teutscher, C., Kapper, C. (eds.): Digitale Medien: Zusammenarbeit in der Bildung, pp. 190-200. Waxmann, Münster, New York (2016).

2. Deterding, S., Khaled, R., Nacke, L. E., Dixon, D.: Gamification: toward a definition. Vancouver, British Columbia: ACM. http://gamification-research.org/wp-content/uploads/2011/04/02-Deterding-Khaled-Nacke-Dixon.pdf, last accessed 2020/06/19 (2011).

3. Wilms, M.: Serious Games - Anwendung digitaler Spiele, insbesondere in den Bereichen Training, Bildung und HealthCare. GRIN, Munich (2009). [Quotes translated].

4. Blair, S., Rillo, M.: Serious Work: Meetings und Workshops mit der Lego® Serious Play®-Methode moderieren. Verlag Franz Vahlen GmbH, Munich (2019).

5. The LEGO ${ }^{\circledR}$ Group: LEGO ${ }^{\circledR}$ Serious Play ${ }^{\mathrm{TM}}$. Open-Source/ <Introduction to LEGO $®$ Serious Play ${ }^{\mathrm{TM}}>$. The LEGO® Group (2010).

6. The LEGO ${ }^{\circledR}$ Group: LEGO ${ }^{\circledR}$ Serious Play ${ }^{\mathrm{TM}}$. Die Wissenschaft von LEGO ${ }^{\circledR}$ Serious Play ${ }^{\mathrm{TM}}$. Spiel. Konstruktion. Imagination. The LEGO ${ }^{\circledR}$ Group (2002). [Quotes translated].

7. Csikszentmihalyi, M., \& Csikszentmihalyi, S.: Optimal experiences: Psychological studies of flow in consciousness. Cambridge University Press, New York (1988).

8. Arnold, R., Nolda, S., Nuissl, E.: Wörterbuch Erwachsenenbildung. 2nd edn. Verlag Julius Klinkhardt, Bad Heilbrunn (2010).

9. Kristiansen, P., Rasmussen, R.: Building a better business using the LEGO® SERIOUS PLAY® method. John Wiley \& Sons, Inc, Hoboken, New Jersey (2014).

10. Techconsult, Deutsche Telekom (eds.): Digitalisierungsindex 2019/2020, https://www.digitalisierungsindex.de/wp-content/uploads/2019/11/techconsult_Telekom_Digitalisierungsindex_2019_GESAMTBERICHT.pdf, last accessed 2020/06/16.

11. Taapken, N., Luh, K.: Wie digital-fit sind Deutschlands Arbeitnehmer? The better the question. The better the answer. The better the world works. Eine EY Studie aus Mitarbeitersicht. EY, (2019).

12. Becker, M.: Personalentwicklung. Bildung, Förderung und Organisationsentwicklung in Theorie und Praxis. Schäffer-Poeschel, Stuttgart (2013). [Quotes translated].

13. Liebscher, J., Schubert, J., Nakhosteen, C. B.: Informelles Wissen durch E-Portfolios sichtbar machen. In: Weiterbildung - Zeitschrift für Grundlagen, Praxis und Trends 2011, Nr.1, S.35-39. (2011). [Quotes translated].

14. Klappacher, C.: Implizites Wissen und Institution. Warum wir mehr wissen, als wir zu sagen wissen: die Rolle des Impliziten Wissens im Erkenntnisprozess. VDM Verlag Müller, Saarbrücken (2006).

\section{ORCID iD:}

Tanja Kranawetleitner (0000-0002-3696-4261), Heike Krebs (0000-0003-2649-657X), Nina Kuhn (0000-0001-7956-3735), Marietta Menner (0000-0003-1779-6343) 